\title{
Acute inversion of a nonpuerperal uterus-a rare case
}

\author{
Sharma N. ${ }^{1}$, Aisha K.D. ${ }^{2}$, Roma J. ${ }^{3}$, Santa A. ${ }^{4}$ \\ ${ }^{1}$ Dr. Nalini Sharma, MS Assistant Professor, ${ }^{2}$ Dr. Aisha Khan Dina, Post graduate Trainee, ${ }^{3}$ Dr. Jethani Roma, Post Graduate \\ Trainee, ${ }^{4}$ Dr. Ahanthem Santa Singh, Professor and Head, all authors are affiliated with Department of Obstetrics and \\ Gynaecology. North Eastern Indira Gandhi Regional Institute of Health and Medical Sciences, Shillong, Meghalaya, India.
}

Corresponding Author: Dr. Nalini Sharma, Assistant Professor, Department of Obstetrics and Gynecology, B1 D, North Eastern Indira Gandhi Regional Institute of Health and Medical Sciences Shillong, Meghalaya. E-mail: nalinisharma100@rediffmail.com

\begin{abstract}
Uterine inversion in a non-pregnant uterus is rare condition usually associated with uterine pathology. Its diagnosis is based on high index of suspicion. Surgery is the main modality of treatment with preferred route being abdominal. A 43-year P5L4A1 previously diagnosed with a uterine fibroid presented in emergency with heavy bleeding P/V. On examination a globular mass $8 * 10 \mathrm{~cm}$ filling the vagina was seen and uterus was not palpated on $\mathrm{P} / \mathrm{V}$ and $\mathrm{P} / \mathrm{R}$ examination. MRI revealed features of inversion secondary to prolapsed fibroid polyp. Diagnosis of uterine inversion was confirmed intra operatively and abdominal hysterectomy was performed after haultain' sprocedure. Postoperative period was uneventful. Diagnosis of uterine inversion requires high index of suspicion and should be looked for and ruled out in a patient previously diagnosed with uterine pathology more so a uterine fibroid. Surgery is the main modality of treatment with preferred route being abdominal. Delineating the ureters via imaging modalities or through preoperative ureteric stenting is prudent to minimize urinary tract injury.
\end{abstract}

Key words: Acute inversion of uterus, Chronic inversion of uterus, Non-puerperal inversion of uterus

\section{Introduction}

Uterine inversion is a pathological condition were the uterus turns inside out, through the cervix. It can be classified based upon the duration from delivery as acute, sub-acute and chronic inversion with prevalence of $83.4 \%, 2.62 \%$ and $13.9 \%$ respectively [1]. Acute inversion is often labeled as puerperal (occurring within 24 hours of delivery) while chronic (after 4 weeks of delivery) are mostly non-puerperal or gynecological.
However rarely non-puerperal inversions may occur acutely and so far in a report, $8.6 \%$ of the non-puerperal uterine inversion had occurred suddenly [2]. Preoperatively uterine inversion possesses a diagnostic dilemma and requires high index of suspicion. The treatment is exclusively surgical; the route for which can be either abdominal or vaginal or by combined abdominovaginal approach.

\section{Case Report}

43 year P5L4A1 with previous all vaginal deliveries presented in gynaecology OPD with complain of heavy bleeding during menstruation with pain lower abdomen for the past 6 months. On examination pallor was absent, other general examination findings were within normal limit. PR-82/min, BP-110/70 mmHg. On per abdomen examination no palpable lump was felt, abdomen was soft and nontender. On per speculum cervix and vagina were healthy, PAP smear was taken. On pervaginal examination uterus was 8 weeks bilateral fornices were non tender and free. Ultrasound revealed a fundal fibroid $6.6 * 5.48 \mathrm{~cm}$ with cystic changes. Bilateral tubes and ovary were within normal limits. Patient was planned for hysterectomy with a diagnosis of abnormal uterine bleeding with leiyomyoma (AUB-L). However, patient was lost to follow. The patient presented to emergency after one month on $7^{\text {th }}$ September 2017 with complain of heavy bleeding per vaginum for 3 hours which bright red in colour was and was associated with passage of clots. She also had acute retention of urine for the same duration. There was no preceding history of amenorrhea, Last menstrual period was on $20^{\text {th }}$ august 2017 , cycles were regular and flow was increased. Urine for Bhcg was negative. Patient gave history of profuse vaginal discharge for last two weeks.

Manuscript received: $18^{\text {th }}$ January 2018

Reviewed: $28^{\text {th }}$ January 2018

Author Corrected: $4^{\text {th }}$ February 2018

Accepted for Publication: $9^{\text {th }}$ February 2018 


\section{Case Report}

She also had vague dull aching pain in lower abdomen. On examination general condition was fair, pallor present, cyanosis, clubbing, icterus, edema were absent. PR-92/min, BP - 100/60 mmHg. On per abdomen examination - no mass was palpable. On per speculum examination a pink fleshy irreducible mass of $8 * 10 \mathrm{~cm}$ with smooth surface, grossly congested was seen filling the vagina. (Figure-1). Cervix was not visualized/ felt, vagina was healthy and there was moderate bleeding present. On bimanual examination cupping felt at the fundus but uterus could not appreciate. A metallic sound was tried to negotiate but could not be passed around the mass. Ultrasonography (USG) revealed uterus bulky with a heteroechoic mass in the lower uterine segment of $6.2 * 6.2 \mathrm{~cm}$. Magnetic Resonance Imaging (MRI) pelvis was done to confirm the diagnosis which showed a well-defined mass in lower uterine segment with features of inversion secondary to prolapsed fibroid polyp. Patient was planned for hysterectomy and preoperatively Bilateral urethral stenting was done to prevent injury to the distal ureters due to distorted anantomy. An abdominal approach was adopted in our case Intraoperative uterine inversion was seen with partial pulling of proximal tubes and round ligaments making a characteristic flower vase appearance. (Figure-2) Bilateral tubes and ovaries were grossly normal. Haultain's procedure was done to release the constricton ring posteriorly and the prolapsed fibroid and uterus was pushed from the vagina. Debulking of the fibroid was done to better delineate the anatomy followed by abdominal hysterectomy. (Figure-3) Post operatively period was uneventful and patient was discharged at postoperative day 7 after stitch removal with an advice to follow up with HPE report. Histopathologic report was consistent with uterine leiomyoma.

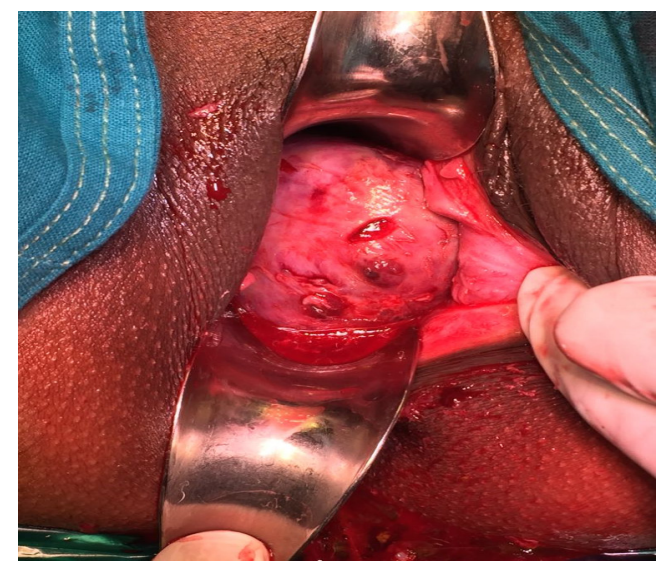

Fig 1: Prolapsed fibroid filling the vaginal cavity to pulling down of uterus and adnexal structures.

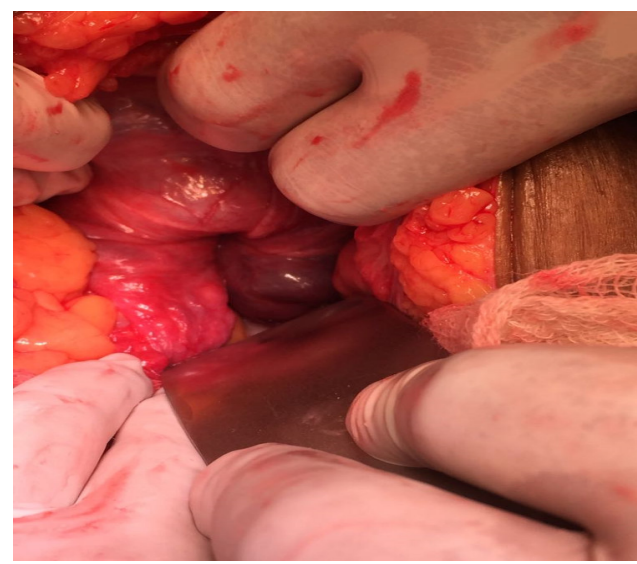

Fig 2: Laparotomy showing characteristic flower vase appearancedue

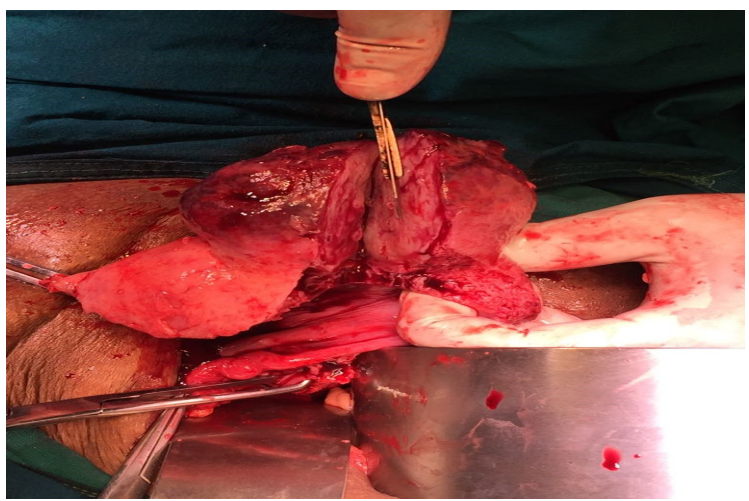

Fig- 3: Debulking the fundal fibroid

\section{Discussion}

Chronic uterine inversion of the nonpuerperal uterus is rare; though no published figures are statedconcerning its incidence [3], it has been reportedjust about 100 timesin the literature since 1940 [4]. Chronic nonpuerperal uterine inversion is frequentlylinked with uterine pathology. Prolapsed fibroids are commonest provocative factor (80-
$85 \%$ of cases) with occasional reports of inversion associated with uterine neoplasm and endometrial polyps [4]. Some contributing factors proposed for uterine inversion are 1) sudden emptying of the uterus (previously distended by a tumor), 2) thinning of the uterine walls due to an intrauterine tumor, and 3 ) cervical dilatation. 
Many risk factors are implicated in inversion of uterus. Puerperal risk factors include precipitate labour, mismanaged or prolonged third stage of labour, uterine atony, premature cord traction prior to placental separation, short umbilical cord, fetal macrosomia, placenta previa and adherent placenta. Thenon-puerperal risks include connective tissue disorders like Marfan's, Ehler's-Danlos syndrome, large uterine fibroids and endometrial cancer. Use of hormone replacement and increased intraabdominal pressure are also considered to promote this pathology [5].

The patient may present with vaginal discharge, irregular bleeding, mass coming out from vagina, coital difficulty, low backache or chronic pelvic pain and urinary retention. Differential diagnoses are sloughing polyp, uterine prolapse ormalignant neoplasm. Ultra sono-graphical features include hyperechoic masswith a central hypoechoic $\mathrm{H}$ shaped cavityin transverse section and a $\mathrm{U}$ shaped depressed groove from the fundus in the centre in longitudinal view [6]. MRI can be useful in preoperative evaluation and sagittal viewsreveal a U-shaped endometrial cavity, while axialimages show a bullseye configuration [7].

Acute uterine inversion is managed conservatively by treating hypovolemia/ shock and manual replacement of the inverted uterus. However surgical intervention is obligatory in chronic uterine inversions as the uterine walls are inelastic and are in a state of complete involution with retraction. The resistance of constricting ring, rigidity of myometrium and the inelastic walls has to be overcome in order to reposition the uterus.

Huntington and Haultain procedures are the commonly used abdominal approaches and Kustner and Spinelli procedures are the two vaginal approaches. Abdominal route is preferred as it facilitates reduced uterine incision, effortless reposition due to traction on round and broad ligament and easy approximation and precise suturing of uterine wall.

Delineating the ureters via imaging modalities or through preoperative ureteric stenting is prudent to minimize urinary tract injury. Lastly, even though the most common

\section{Case Report}

cause of non-puerperal prolapse is a preexisting uterine fibroid, biopsy is mandatory keeping in mind a minimal but obvious risk of malignancy.

\section{Conclusion}

Diagnosis of uterine inversion requires high index of suspicion and should be looked for and ruled out in a patient previously diagnosed with uterine pathology more so a uterine fibroid. Surgery is the main modality of treatment with preferred route being abdominal. Delineating the ureters via imaging modalities or through preoperative ureteric stenting is prudent to minimize urinary tract injury.

\section{Funding: Nil, Conflict of interest: Nil Permission from IRB: Yes}

\section{References}

1. Dali SM, Rajbhandari S, Shrestha S. Puerperal inversion of the uterus in Nepal: case reports and review of literature.J Obstet Gynaecol Res.1997Jun;23(3):319-25

2. Gomathy E, Agarwal Y, Sreeramulu PN, Sheela SR Non-puerperal uterine inversion with an ovarian tumor -a rare case. Int J Pharm Biomed Res.2011;2: 74-75.

3. Dhaiya K, More RH, More H, Dahiya A. Nonpuerperal uterine inversion caused by fibroid polyp associated with squamouscell carcinoma of the cervix. Journal of Gynaecologic Surgery 2009; 25: 37-40.

4. Takano K, Ichikawa Y, Tsunoda H, Nishida M. Uterine inversion caused by uterine sarcoma: a case report. Jpn J Clin Oncol. 2001 Jan;31(1):39-42.

5. Kilpatrick CC, Chohan L, Maier RC. Chronic non puerperal uterine inversion and necrosis: a case report. J Med Case Rep. 2010 Nov 25;4:381. doi: 10.1186/17521947-4-381.

6. Hsieh TT, Lee JD. Sonographic findings in acute puerperal uterine inversion. J Clin Ultrasound. 1991; 19: 306-09.

7. Lewin JS, Bryan PJ: MR imaging of uterine inversion. J Comput Assist Tomogr1989;13:357-359.

\section{How to cite this article?}

Sharma N, Aisha K.D, Roma J, Santa A. Acute inversion of a nonpuerperal uterus-a rare case. Obs Rev:J obstet Gynecol 2018;4(1):18-20.doi: 10.17511/joog.2018.i01.04. 